\title{
PROCESS OF BECOMING A CERTIFIED PUBLIC ACCOUNTED IN TURKEY
}

\section{DOI: 10.17261/Pressacademia.2019.1108 \\ PAP-V.9-2019(55)-p.299-303}

\section{Yasemin Kocaoz ${ }^{1}$, Suat Teker ${ }^{2}$}

${ }^{1} 1$ şık University, Graduate School of Social Sciences, Maslak Campus, Sariyer, İstanbul, Turkey. yaseminkocaoz@cozummusavirlik.com.tr, ORCID: 0000-0003-0162-0773

${ }^{2}$ Işık University, Maslak Campus, Sariyer, Istanbul, Turkey.

suat.teker@isikun.edu.tr, ORCID: 0000-0002-7981-3121

\section{To cite this document}

Kocaoz, Y., Teker, S., (2019). Process of becoming a certified public accounted in Turkey. PressAcademia Procedia (PAP), V.9, p.299-303

Permemant link to this document: http://doi.org/10.17261/Pressacademia.2019.1108

Copyright: Published by PressAcademia and limited licenced re-use rights only.

\section{ABSTRACT}

Purpose- The first state that comes to mind when we hear the word accounting in Turkey, is a tax and money. Accounting persons are also accountants. The title of the accountant; It does not matter whether he/she is a Public Accountant or Certified Public Accountant. He/She is just an accountant. The accountant receives a monthly fee for the service, so the client considers the accountant to be an employee and does not require any tax payment. If a tax payment arises, he considers it responsible as an accountant and thinks that he has harmed himself. Methodolgy- In order to obtain these titles, a professional member goes through many stages and gains competence. While the professional accountants are divided into three groups, the legal titles of these three groups are Independent Accountant, Certified Public Accountant and Certified Public Accountant (SM, SMMM, and YMM).

Findings- Can the members of the profession see the dignity they deserve, starting from university education, internship, after the proficiency exams and at the end of the licensing process? Members of the profession have developed themselves in the professional sense from the past to the present. With the introduction of the Uniform Accounting system in 1993 and the spread of computerized accounting systems, this profession has become more technical.

Conclusion- While the members of the profession provide good services to their customers, they also act as a fair bridge between the state and them. The difficulties, struggles and solutions in these processes, the participation of women professionals in the profession, the difficulties they face as women and their contributions are of curiosity. A questionnaire was conducted with 100 professionals and the answers to the related issues were sought.

Keywords: Intern, public accountant, certified public accounted, licensing

JEL Codes: M10, M12

\section{TÜRKIYE’DE MALI MÜŞAVIR OLMA SÜRECI}

\section{ÖZET}

Amaç-Türkiye'de muhasebe kelimesini duyduğumuzda ilk akla gelen devlet, vergi ve paradır. Muhasebe işlerini yürüten kişiler de muhasebecilerdir. Muhasebecinin unvanının; Serbest Muhasebeci, Mali Müşavir veya Yeminli Mali Müşavir olmasının bir önemi yoktur. Sadece muhasebecidir. Muhasebeci her ay hizmet karşılığı ücret alır, bundan dolayı müşteri muhasebecisini elemanı gibi görür ve herhangi bir vergi ödemesi çıkmasını istemez. Bir vergi ödemesi çıkarsa bunun sorumlusunu muhasebeci olarak görür ve kendisini zarara uğrattığını düşünür.

Yöntem- Bir meslek mensubu bu unvanlara sahip olabilmek için birçok aşamadan geçerek, yetkinlik kazanır. Muhasebe meslek mensupları üç guruba ayrılırken, bu üç gurubun yasal unvanları Serbest Muhasebeci, Serbest Muhasebeci Mali Müşavir ve Yeminli Mali Müşavirdir.(SM, SMMM, ve YMM)

Bulgular-Üniversite eğitiminden başlayarak, stajyerlik, sonrasında yeterlik sınavları ve ruhsat alma süreci sonunda acaba meslek mensupları hak ettikleri saygınlığı görebiliyor mu? Meslek mensupları geçmişten günümüze, mesleki anlamında kendini geliştirmektedir. 1993 yılında Tek Düzen Muhasebe sisteminin yürürlüğe girmesi, bilgisayarlarlı muhasebe sistemlerinin yaygınlaşmasıyla birlikte, bu meslek daha da teknik bir yapıya geçmiştir.

Sonuç- Meslek mensupları müşterilerine iyi hizmet verirken, aynı zamanda devlet ile aralarında adil bir köprü görevi de üslenmektedir. Bu süreçlerde yaşanılan zorluklar, mücadeleler ve çözüm yolları, kadın meslek mensuplarının mesleğe katılımı, kadın olarak yaşadıkları zorluklar ve katkıları merak konusudur. 100 meslek mensubu ile yapılan bir anket ile bu sorulara v-cevap aranmıştır.

Anahtar Kelimeler: Stajyer, serbest muhasebeci, SMMM, YMM, ruhsatlandırma.

JEL Kodları: M10, M12 


\section{GíRiş}

Muhasebeci veya Mali Müşavir meslek üvnavlarını, birçoğumuz çevremizden duymuşuzdur. Ticaret lisesinde okuyarak ve hatta 2 ay bilgisayarlı muhasebe kursuna gidilerek te muhasebeci olunabilir. Alternatif olarak, bir muhasebe bürosunda uzunca bir süre çalışılarak da muhasebeci olunabilir. Bu bakış açısıyla, muhasebeci olmanın ne kadar kolay olduğu düşünülebilir. Dört yıl süren üniversite eğitimi, ardından 3 yıl süren staj dönemi ve bitmek bilmeyen sınavlar sonrasında, mali müşavir ünvanı ile alınan meslek icra etme ruhsatı da önemsiz görünebilir. Kimi meslek mensubu, bu ruhsat ile kendi mali müşavirlik ofisin, açabilir, kimisi bordrolu olarak şirketlerde çalışmayı tercih ediyor olabilir. Bu çalışmada, muhasebecilik mesleğinin işleyişi, topluma katkısı, bitmek bilmeyen iş yükünü ve meslek mensubu olmanın tüm aşamaları anlatılmaktadır. Mali müşavirler günlük hayatta sadece iş yükü ile değil, mücbir sebepler ile de mücadele etmek zorunda kalmaktadır. Kadın meslek mensuplarının da meslek pastasından pay alma çabası, bir kadın-anne bir eş ve iş insanı olarak yaşadığı tüm zorluklarla mücadelesinin sonuçlarıdır. Diğer mesleklerde olduğu gibi, muhasebe mesleğinde de değer yargılarında çelişkiye düşme, kurallarda ve kararlarda anlaşamama ve mesleki problemler görülmektedir. Fakat bu sorunlara rağmen, muhasebe mesleği mensubu; doğruyu söylemek, dürüst olmak ve tutarlı olmak zorundadır. Çünkü işletmeler, ekonomik hayatın en küçük iktisadi birimleridir. Ekonomik hayatın başarısı, dürüstlüğü, toplumun ve bireyin ekonomik refahını etkilemektedir. (AYBOĞA, 2003). İşletmeler, toplum ve devlet için; mali müşavirlik mesleği önemli bir konumdadır. Takip eden bölümlerde, muhasebe meslek mensubu olabilme süreci anlatılmaktadır.

\section{EĞiTiM}

Mali müşavir olabilmek için, fakülte mezunu olmak gerekir. İktisat, işletme, kamu yönetimi, uluslararası ilişkiler, maliye, çalışma ekonomisi ve endüstri ilişkileri, siyaset bilimi ve kamu yönetimi, ekonometri, siyaset bilimi, uluslararası finans, ekonomi, bankacılık ve sermaye piyasası, hukuk, bankacılık ve finans bölümlerinden birinden mezun olmak gerekir. Sayılan bu bölümmezun olmak, mali müşavir olabilmek için yeterli midir? Cevap, "hayır". Asıl meslek mensubu olma süreci bundan sonra başlar.

Mezun olduktan sonra, bir mali müşavire bağlı olarak bir işletmede veya muhasebe bürosunda fiili 3 yıl staj yaparak çalışmak gerekir. Bu 3 yıllık sürede, hem staj yapmak hem de işi öğrenerek, mali müşavir olunur diye düşünlebilir. Fakat staj sürecine başlamak için de bir sınavı gşrek gerekir. Stajyer adayının bağlı bulunduğu ilin muhasebe meslek odasında, ilk olarak bir staj dosyası açtırması gerekir. Dosya açtırmak için 1500 TL'lik staj dosya ve başvuru bedeli ödenmelidir. Staj sınavını alan bir aday, 130 sorudan oluşan bir sınava tabi tutulur. Bu sorulardan 30 tanesi genel kültür ve genel yetenek; 100 tanesi ise meslek bilgisinden oluşur. Bir staja başlama sınavına 17.000-20.000 kadar kişi katılır ve \%10 civarında başarı olur. Sınav geçme notu, en az 60'tır. Meslek bilgisi sorulan kısımda; 15 dersten sorumlu tutulan adaylar, çok zorlanır. Sınavda; Türkçe, matematik, tarih ve yabancı dilden 30 soru gelir. Finansal muhasebe, maliyet muhasebesi, mali tablolar analizi, muhasebe denetimi, ekonomi, maliye, meslek hukuku, iş hukuku, vergi hukuku, ticaret hukuku ve borçlar hukuku derslerinden ise, 100 soru sorulur. (TESMER, 2019). Sınava girenlerin en iyi olasılıkla \%10 kadar başarılı olabilir. Eğer o sınav döneminde 2000 kişi stajyer olarak alınacaksa, 2001. kişi başarısız sayılır. Sınava hazırlanan ve başarılı olan aday stajını başlatma hakkı kazanıyor.

\section{STAJ}

Staj sınavını kazanan adaylar, bir mali müşavire bağlı olarak bir işletmede veya bir muhasebe bürosunda stajyer olarak, 3 yıl çalışmalidir. Eğer adayın daha önceden bir deneyimi yoksa, stajını başlatacak bir işyeri bulması kolay değildir.

\section{Staj 3 yıldan daha kısa bir sürede tamamlanabilir mi?}

Stajyer hedefine ulaşmak için, meslek stajııı kısa sürede bitirmek ister. Bir stajyer, meslek odasının kurslarına giderse, stajı kısalabilir. En etkili kısaltma yöntemi ise, stajyerin yüksek lisans yaparak bitirme projesini veya yüksek lisans tezini diplomasıyla birlikte odaya teslim etmesidir. Yüksek lisans derecesini almak, staj süresini 1 yıl kısaltır. Stajyerler, hem kariyerlerinde ilerlemek, hem de yüksek lisans eğitimini almak isterler. Ancak bir stajyerin hem yoğun bir iş yükü ile çalışması ve hem de ağır bir yüksek lisans eğitimini bir arada yürütebilmesi, çok zordur. Ayrıca, bir stajyerin aldığı düşük bir maaş ile, yüksek lisans eğitim giderini karşılaması herkes için mümkün değildir.

\section{Staj bitince, mali müşavir olunabilir mi?}

Staj bittikten sonra, hemen mali müşavir olunamaz. 8 dersten oluşan bir yerlik sınavının aşılması gerekir. Yazılı yapılan bir sınavdır, her dersten en az 50 alınması ve genel not ortalamasının en az 60 olması gerekir. Sınav başarı belgesi alındıktan ve gerekli harçlar ödendikten sonra, mali müşavir ünvanı kanazılır.

\section{Mali müşavir olduktan sonra, neler yapablirim?}

İnsanlar mesleklerini seçerken, rahat çalışma koşullar olan ve para kazandıran meslekleri seçme eğilimindedir. En çok sevilen ve başarıı olunmak istenen meslekleri seçmek, toplumda biraz lüks gibi görülebilir. Mali müşavirlik mesleği de para kazandıran bir meslek gibi görünür ama gerçekten öyle midir? Mali müşavir olunca, iki yoldan biri tercih edilmelidir. Mali müşavir kendi bürosunu açıp, bağımsız bir şekilde çalışabilir veya bir şirkette veya başka bir muhasebe bürosunda da bağımlı mali müşavir olarak çalışabilir. Eğer ikinci tercih ediliyorsa, bir mali müşavir olmanın çok ta önemi yoktur. Ilgili kişiye olan kazanımı, bir unvan ve aldığı maaşta biraz artı̧ demektir. Eğer birincisi tercih ediliyorsa, mali müşavirin işi çok daha zordur. Yetkin ve uygun elemanları bulmak, müşteri bulmak, bulunan müşterileri portföyde tutmak, tüm işletme giderlerini zamanında karşılamak ve faaliyetlerden doğan vergileri ödemek gibi.

\section{Vergi mükellefi ve mali müşavir ilişkisi}

Vergi mükellefleriyle mali müşavirlerin ilişileri, kanunda yer alan hükümler bakımından aşă̌ıda sunulan tablodaki gibidir. Ancak mükelleflerin talepleri bunlarla sınırlı değildir. Sektörde yaşanan haksız rekabet nedeniyle, mali müşavirler faaliyet alanına girmeyen konularda da müşteri çekebilmek adına hizmet vermeye kendilerini zorunlu hissetmektedir. 


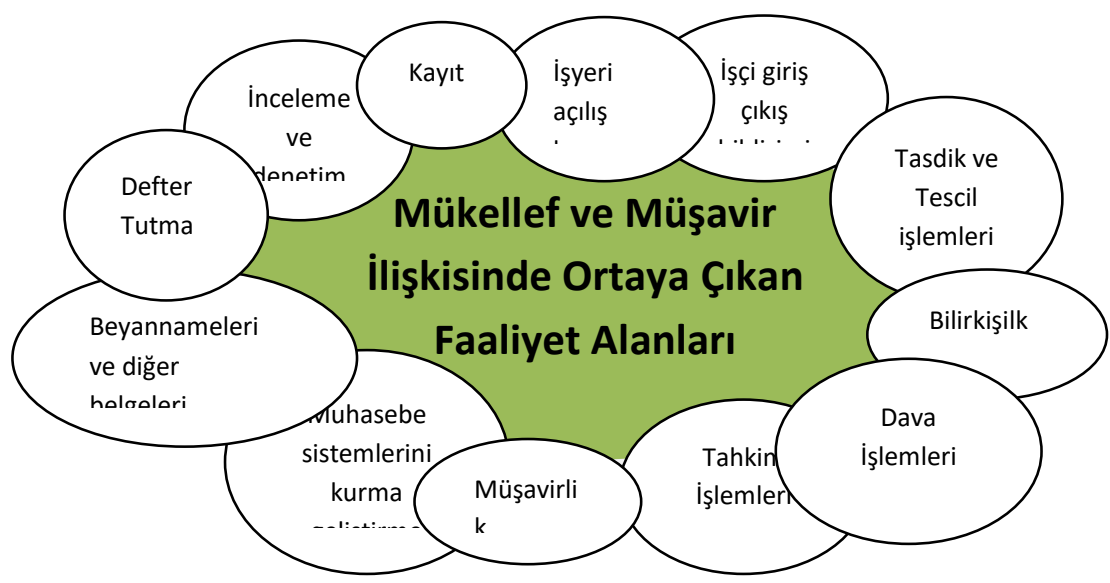

(HEPAKSAZ, 2018)

\section{Mali müşavirin büro açma serüveni}

Ofis açma isteyen bir mali müşavir, önce bir büro kiralamalıdır. Ofisin dizaynı, masa takımı, koltuk takımı bilgisayar yazıcı ve ofis programı vs ihtiyaçların tamamlanması gerekir. Ofis açıldıktan sonra, ilk adımda tanıdıkların muhasebe defterlerini tutmak, iyi bir başlangıç olabilir. Fakat bu müşteri sayısı, ofisin elektrik, su, ısıtma ve soğtma gibi genel giderlerini karşılamaya yetmez. ilave olarak, aylık kira ödemeleri de vardır. Müşteri çekmek için, reklam yapmak iyi bir fikir olabilir ama meslekte reklam yapma yasağı vardır. "Meslek mensupları, mesleki faaliyetleri kapsamında işin kabulü, reddi, yürütülmesi ve sona ermesi ile reklam yasağı kapsamına giren her türlü faaliyetlerine ilişkin olarak haksız rekabete neden olacak eylem ve davranışlarda bulunamazlar." (ODASI, https://www.ismmmo.org.tr/Mevzuat/Yonetmelikler, 2019)

Eğer kira ve sabit giderleri karşılayacak kadar bir müşteri portföyü yoksa, büro açmak mantıkı bir seçenek değildir. Bu nedenle, birçok mali müşavir büro açıp bağımsız çalışmak yerine, bir şirkette bordrolu çalısmayı tercih etmek zorunda kalmaktadır. Her meslekte bu zorluklar vardır diye düşünülebilir, ancak mali müşavirlik hizmeti bir kere verilen bir hizmet değil, devamlılık arz eden bir meslektir. Her ay gelir ve gider faturalarının işlenmesi ve aylık/3-aylık/yıllık beyannamelerin verilmesi gerekir ve bu işler için müşteri ile en az 1 yıllık sözleşme yapılır. Bu sebeple, müşterilerin yeni bir mali müşavir arayışı genelde yıl sonunda, yeni sözleşme yapılacağı zamanlarda ve fiyat artışı konusu konuşulduğundadır. Esnaflar kendi aralarında konuşurken, en ucuza defter tutan muhasebecinin kim olduğunu sorarlar ve sonunda en ucuz olana yönelirler. Sonunda, müşteri kaçırmak istemeyen muhasebeci için asgari tarifenin altında ücret söyleyerek, sözleşmesini yapar. Büyük firmalarda genelde ödenecek aylık ücret yerine, daha çok beşeri ilişkiler ön ğlan çıkmaktadır. Gelir kaynağını mali müşavirlik hizmeti vermek olan meslek mensuplarının aylık kazançlarını, takip eden bölüm incelemektedir.

\section{ISMMMO 2019 YILI DEFTER TUTMA ASGARI ÜCRET TARIFESI}

İstanbul 2019 yılı asgari ücret tarifesinden bazı örnekler, aşağıdaki tabloda yer almaktadır. İşletme niteliğine, iş̧̧ sayısına, alım satım, hizmet imalat türüne göre, defter tutma ücretleri değişiklik göstermektedir.

\begin{tabular}{|l|c|c|c|}
\hline DEFTER TUTMA (2019 YILI) & işçisiz & $\mathbf{1 - 3}$ işçi & $\mathbf{4 - 9}$ işçi \\
\hline iş̧LTME DEFTERI(ALIM-SATIM) & $196 \mathrm{TL}$ & $230 \mathrm{TL}$ & $250 \mathrm{TL}$ \\
\hline SERBEST MESLEK KAZANÇ DEFTERi & $226 \mathrm{TL}$ & $242 \mathrm{TL}$ & $258 \mathrm{TL}$ \\
\hline BiLANÇO ESASINA GÖRE ŞAHIS FIRMASI (HIZMET) & $555 \mathrm{TL}$ & $600 \mathrm{TL}$ & $646 \mathrm{TL}$ \\
\hline LiMiTED ŞiRKETi (HiZMET) & $646 \mathrm{TL}$ & $691 \mathrm{TL}$ & $747 \mathrm{TL}$ \\
\hline ANONIM ŞiRKETi (HIZMET) & $679 \mathrm{TL}$ & $747 \mathrm{TL}$ & $856 \mathrm{TL}$ \\
\hline KOOPERATiF, DERNEK VE VAKIFLAR (ESNAF KEFALET) & $210 \mathrm{TL}$ & $235 \mathrm{TL}$ & $252 \mathrm{TL}$ \\
\hline
\end{tabular}

(ODASI, https://www.ismmmo.org.tr, 2019)

Bir meslek mensubunun asgari ücret tarifesine göre defter tuttuğu varsayımı altında; bürosunun aylık genel giderlerini karşılaması için en az 10 işletme defteri ve 2 bilanço usulü defter tutması gerekir. Ayrıca, bir personel de istihdam ederse (asgari ücretli maaş ve SGK maaliyeti aylık 3040 TL'dir), tuttuğu defter sayısını ikiye katlamak zorundadır. Bu nedenlere dayanarak, yeni mali müşavir olmuş bir kişinin büro açması başlangıçta çok mantıklı bir seçenek Imayacaktır.

\section{Meslekte kadın mali müşavir olmak}

Mali müşavir olmak zordur, ama kadın mali müşavir olmak biraz daha zordur. Türkiye'deki mali müşavirleri kadın-erkek oranları aşağıdaki taboda sunulmuştur. Bu oranda son yıllarda bir artış gözlemlenmesine rağmen, kadın meslek mensuplarının toplam içindeki oranı yaklaşık $\% 40^{\prime}$ tir. 
SM-SMMM-YMM'lerin Türkiye Genelindeki Kadın Erkek Dağııımı (2018)

\begin{tabular}{|l|c|c|c|c|}
\hline CINSIYET & SM & SMMM & YMM & TOPLAM \\
\hline KADIN & 1528 & 29909 & 382 & 31819 \\
\hline ERKEK & 7116 & 68632 & 4414 & 80162 \\
\hline
\end{tabular}

(https://turmob.org.tr/FaaliyetRaporlari/9b50fa44-4d0f-4177-9e9f-e0cb075c8724/calisma-donemine-bakis--1-, 2018)

"Kadın bir meslek mensubu, ister evli olsun ister bekar olsun, mesleğin yoğunluğu sebebiyle, ailevi sorunlar yaşayabilmektedir. Bazı meslek mensupları ev yaşantıları ile ilgili problemler nedeniyle, meslek değiştirmeyi düşündüklerini ve hatta bunu gerçekleştiren meslektaşları olduğunu dile getirmişlerdir. Bunun önüne geçilebilmesi için toplumun aile ve ev ile ilgili tüm sorumluluğu kadına bırakmaktan vazgeçmesi gerekmektedir." (Ağca \& Yalçın, 2009)

\section{TÜRKIYE' MALI MÜŞAVIR OLMANIN ZORLUKLARI: ANKET ÇALIŞMASI}

Türkiye'de mali müşavir olma sürecinin ne kadar zor olduğu ve bu süreci tamamladıktan sonra, meslekte devam edebilmenin daha zor olduğu, önceki bölümlerde anlatılmıştır. Meslek mensupları, toplumda hak ettikleri saygıyı görüyorlar mı veya kaliteli çalışma olanakları var mı, gibi alanları kapsayan anket çaloşması sonuçları, aşağıda sunulmuştır. Meslek mensupları arasında yapılan bu ankete, toplam 100 dönüş alınmıştır. Ankete alınan yanıtlar, söylece yorumlanabilir;

\section{Bu mesleği neden seçtiniz?}

Katılımcıların \%59’u bu mesleği sevdiği için yapma kararı alırken, \%41'i aile baskısı, yapacak meslek bulamadığı için ve maddi kazancın iyi olacağını düşündüğü için, seçtiğini söylemiştir. Bu veriler, meslek personelinin yaklaşık yarısının, bu mesleği çok istemeden seçtiklerini göstermektedir.

\section{Çalışma şekliniz nedir? Neden bu çalışma şekliniz tercih ettiniz?}

Katılımcıların \%28'i tek başına büro yönetirken, \%25'i ise personel kadrosu ile çalışmaktadır. \%47'si ise büro açmak yerine, şirket veya başka meslek mensubunun yanında bağımlı çalışmaktadır. Bu durumun sebebini ise; \%63'ü bağımlı çalışmanın riskinin düşük ve şartlarının daha iyi olmasına bağlarken, \%37'i ise serbest çalışmak istemesine rağmen, şartların bağımlı çalışmaya yöneltmesine bağlamaktadır.

\section{Çalışma koşulları, çalışma ve özel hayatınızı nasıl etkiliyor?}

Katılımcılardan \%81'i çok yoğun çalışmaktan kendilerine ve özel hayatlarına zaman ayıramamaktan yakınırken, sadece\% 9 u rahat bir çalışma hayatının olduğundan bahsediyor. Dönemsel verilmesi zorunlu beyanların zamanında yetişmesi ve devamlı angarya işlerin çıkması, devletin memurlarının yapması gereken işlerin de online üzerinden verilmesi ile bu işlerin de mali müşavirlere yaptırılması, çalışma yoğunluğunu arttırmaktadır. Son dönemde poşet beyannamesi verilmesi sorumluluğu da yine mali müşavirlere yüklenmiştir ve maalesef mali müşavirler bu ilave hizmet karşılığında hiçbir ücret alamamaktadır.

\section{Türkiye'de kadın SM-SMMM-YMM oranlarının düşük olmasını nasıl değerlendiriyor sunuz?}

Türkiye'de meslek mensuplarının \%60'i erkek iken \%40’u kadındır. Katılımcılar bunun sebebini, SMMM sürecinin uzun olması (\%37), mükelleflerin erkek SMMM tercih etmesi (\%28), kadınlar için çalışması yoğun bir meslek olması (\%21) ve kadınların mükellef edinmesinin zorluğu (\%14) olarak görmektedir.

Mali müşavir olma süreci çok uzun olarak görülüyorsa, bu durum niçin erkek adaylar için geçerli değildir? 4 yıllık bir üniversite eğitimi, 3 yıllık bir staj süreci ve 1 yıl yeterlilik süreciyle birlikte, aradaki sınavlara hazırlık aşamaları ile, toplamda 9-10 yıllık bir süreçtir. Liseyi 18 yaşında bitiren bir bayanın, 10 yıl daha bu süreci yaşaması yerine, şirketlerde muhasebe veya finans veya bankalara yönelmesi daha cazip gelebiliyor.

Çalışma yoğunluğu açısından bakılırsa, zor bir meslek midir? Cevap, "kesinlikle evet” olmalıdır. Erkek meslek mensupları açısından çok yoğun bir meslek, ancak kadınlar açısından durum biraz daha farklıdır. Kadın çalışanların bilindiği üzere, doğum izinleri vardır. Doğumdan önce 8 hafta, doğumdan sonra 8 hafta olmak üzere, toplamda 16 haftalık yasal izin süresi vardır. Kadınlar bu sürede geçen 16 haftalık ücretini de SGK'dan alabilir. Doğum sonrasında 6 ay ücretsiz izin hakkı vardır ve işveren bu izin hakkını kullanmasına izin vermek zorundadır. Acaba kadın mali müşavir, bu hakkı kullanabilir mi? Elbette kullanabilir ama çalışanı için. Kadın çalışanı varsa, çalışanının bu hakları kullanmasına izin vermek zorundadır. Acaba mali müşavir kendi için kullanabilir mi? Cevap, kısaca hayır olacaktır. Meslek mensubu ve ofisi olan bir kadının bu hakkını kullanması, pratikte mümkün değildir. Defter tutma işleri ve zamanında verilmesi gereken beyannameler, bekletilemez. İşleri en az mali müşavir kadar iyi yapan bir çalışanın bulunması ve yaptığı tüm işlerin kontrol edilmesi gerekir.

\section{SONUÇ}

Her mesleğin zorlukları vardır. Kadın veya erkek cinsiyet ayrımı olmaksızın, her bireyin dilediği mesleği seçebilme, icra edebilme ve çalışılabilir şartlarda yapma hakkı olmalıdır. Kadın veya erkek meslek mensuplarının en büyük problemi, bu meslekte "mücbir sebep" tanımının olmamasıdır. Beyanname vermenin son günü ise ve başka bir çalışan yoksa, mali müşavirin hasta olması, hastası olması veya cenazesi olması, bu durumu değiştirmez.

Bir millet vekilinin, mecliste "MÜCBIR SEBEP" problemine vurgu yapmak için anlattığı, yaşanmış bir hikaye tüm bu anlatılanları bir bakıma özetlemektedir. Bir mali müşavir baba, evladını trafik kazasında kaybediyor. Çocuğunun def'in işlemlerini büyük bir üzüntü içerinde yaptıktan sonra, ofisine gidiyor. Gece 12.00 ’ye kadar vermek zorunda olduğu beyannamelerini onaylıyor. Sonra, masa başında hiç kalkmadan sabaha kadar hıçkırıkla boğuluyor, acısını yaşıyor. Hangi sebep, hangi meslek, evlat anne baba kardeş eş ölüm acısından daha önemlidir. Bu meslek 
mensubu, bu sorumluluğunu mesleğine ve mükellefine duyduğu saygı için yapmıştır. Beyannameler cezaya kalamaz mıydı? Sosyal medyadan birçok meslek mensubunun başına gelen benzer olaylar da bu duruma vurgu yapmaktadır. Beyan dönemlerinde ameliyatını erteleyenler, hastanede son nefesini veren yakının yanında olamayanlar, masa başında iş yetiştirirken kalp krizi geçirerek vefat edenlere, sıkça rastlanır oldu.

\section{KAYNAKÇA}

Ağca, A., Yalçın, N. (2009). Muhasebe mesleğinde kadın olmak sorun teşkil eder mi?. Dumlupınar Universitesi Sosyal Bilimler Dergisi, S.24, $1-5$.

Ayboğa, D. (2003). Globalleşme sürecinde ülkemizde muhasebe mesleği ve meslek mensuplarının eğitimi. Marmara Üniversitesi iktisadi ve Idari Bilimler Dergisi, C.18, S.1, 327-359.

Hepaksaz, E. (2018). Vergi mükellefi - mali müşavir ilişkilerinde yetki -sorumluluk sorunsalı, genel sorunlar ve bazı yargı kararları ışığında değerlendirmeler. Trakya Üniversitesi Sosyal Bilimler Dergisi, C.20, S.1, 233-251.

https://turmob.org.tr/FaaliyetRaporlari/9b50fa44-4d0f-4177-9e9f-e0cb075c8724/calisma-donemine-bakis--1-. (2018).

https://www.ismmmo.org.tr

https://www.ismmmo.org.tr/Mevzuat/Yonetmelikler.

https://www.tesmer.org.tr. 